\title{
EGFR Regulates Iron Homeostasis to Promote Cancer Growth through Redistribution of Transferrin Receptor 1
}

Biao Wang, ${ }^{1,3}$ Jiqin Zhang, ${ }^{1,3}$ Fei Song, ${ }^{1}$ Mi Tian, ${ }^{1}$ Bizhi Shi, ${ }^{1}$ Hua Jiang, ${ }^{1}$ Wen Xu, ${ }^{1}$ Hai Wang, ${ }^{1}$ Min Zhou, ${ }^{1}$ Xiaorong Pan, ${ }^{1}$ Jianren Gu, ${ }^{1}$ Shengli Yang,,${ }^{1}$ Liyan Jiang, 2,* and Zonghai $\mathrm{Li}^{1}{ }^{*}$

1State Key Laboratory of Oncogenes and Related Genes, Shanghai Cancer Institute, Renji Hospital, Shanghai Jiao Tong University School of Medicine, Shanghai 200032, PR China

${ }^{2}$ Respiratory Department, Shanghai Chest Hospital, Shanghai Jiaotong University School of Medicine, No. 214, West Huaihai Road, Shanghai 200030, PR China

${ }^{3}$ Co-first author

"Correspondence : zonghaili@shsmu.edu.cn (Z.L), Address: No.25/Ln2200, XieTu Road, Shanghai 200032, P.R.China. Tel: 86-21-64436601; Fax: 86-21-64432027; jiang_liyan2000@126.com (L.J), Address: No.241, Huaihai (W.) Rd, Shanghai, 200030, P.R.China. Tel: 86-21-22200000*3801; Fax: $86-21-22200000$ 


\section{Abstract}

Dysregulation in iron metabolism can lead to a wide range of diseases including cancer. Iron-regulatory proteins (IRPs) and iron responsive elements (IREs) have been established as post-transcriptional regulators of intracellular iron homeostasis. The role of other pathways involved in this process, however, remain largely unknown. Here we report that epidermal growth factor receptor (EGFR), an oncogenic driver, binds to and regulates the subcellular distribution of transferrin receptor 1(TfR1) through its tyrosine kinase activity and thus is required for cellular iron import. Inactivation of EGFR reduces the cell surface TfR1 expression, which leads to decreased iron import due to impaired TfR1-mediated iron uptake. This damaged iron assimilation results in cell cycle arrest and growth inhibition, which can be partially rescued by non-Tf-bound iron supplements. Evaluation of non-small cell lung cancer samples reveals a positive correlation between EGFR activation and membrane TfR1 expression. Our findings uncover a new role of EGFR in modulating cellular iron homeostasis through redistribution of TfR1, which is essential for cancer development and progression.

Keywords: EGFR; TfR1; Iron homeostasis; Tyrosine phosphorylation 


\section{Introduction}

Iron is an essential element required for diverse biological processes such as intermediate production, DNA synthesis and cell cycle progression $(1,2)$. Aberrant iron metabolism is associated with cancers (3), and understanding the molecular mechanism is crucial for their therapeutics.

Iron from diet is absorbed within the proximal duodenum and is then transported into the blood, where it binds to transferrin $(\mathrm{Tf})(4,5)$. Tf-bound iron interacts with TfR1 on the cell surface and is internalized to endosome, then the ferric iron is released from transferrin and reduced to ferrous iron $\left(\mathrm{Fe}^{2+}\right)$. The Tf-TfR1 complex is sorted into the recycling endosomes and returned back to the cell surface, where participates in another round of iron import (6, 7). In the past few years, studies have demonstrated that the effects of iron overload and several iron metabolism related proteins are associated with the tumorigenesis of lung cancer and growth of lung cancer cell(8-10). Studies also have proved that cancer cells have higher TfR1 expression compared to normal cells $(11,12)$. However, how TfR1 is regulated in cancer has not been completely understood.

Epidermal growth factor receptor (EGFR) is a member of cell surface receptors with tyrosine kinase activity. It drives the growth of tumors through overexpression or overactivation mutations (13). Enhanced proliferative effect from EGFR requires increased intermediate production and faster DNA synthesis. Although evidences suggest that EGFR may take part in the iron 
metabolism, convincing evidence is lacking regarding whether there is a direct regulation of EGFR in TfR1-mediated cancer iron metabolism.

To dissect the biochemical function of EGFR in iron metabolism, we performed loss and gain function studies in lung cancer cells. Our studies revealed that EGFR regulates TfR1 distribution to modulate iron uptake and is essential for maintaining cellular iron homeostasis and cell proliferation. 


\section{Materials and methods}

\subsection{Cell Culture}

Human lung adenocarcinoma cell strain PC-9, A549 and human embryonic kidney (HEK) 293T cells obtained from American Tissue Culture Collection (ATCC, Manassas, VA, USA) were cultured DMEM (Gibco, Grandlsland, NY, USA) medium supplemented with $10 \%$ fetal bovine serum (Gibco, Grandlsland, NY, USA). Human lung adenocarcinoma cell strain HCC827 and H1975 cells were obtained from ATCC and cultured in RPMI 1640(Gibco, Grandlsland, NY, USA) medium with 10\% FBS.

\subsection{Western Blotting}

Cells were harvested in cold phosphate-buffered saline (PBS) and washed by 3 times. Then the cells were lysated by using mammalian protein extraction reagent (M-PER) (Thermo, Waltham, MA, USA) containing a cocktail of protease inhibitors (Sangon Biotech,Shanghai, CHINA), $1 \mathrm{mM} \mathrm{NaF}$ and $1 \mathrm{mM} \mathrm{Na} \mathrm{VO}_{4}$. The lysates were separated by sodium dodecyl sulfate-polyacrylamide gel electrophoresis and analzyed by immunoblotting with the indicated antibodies.

\subsection{Cytoplasmic and Cell Surface Membrane Fractionation Extraction}

The components of cell membrane and cytosol were extracted by 
Mem-PER Plus Membrane Protein Extraction Kit (Thermo, Waltham, MA, USA) and NE-PER ${ }^{\mathrm{TM}}$ Nuclear and Cytoplasmic Extraction Reagents (Thermo, Waltham, MA, USA) according to the manufacturer's instructions.

\subsection{Co-immunoprecipitation Assay}

For immunoprecipitation assay, $2 \mathrm{mg}$ proteins were immnoprecipitated by the specific antibodies at $4^{\circ} \mathrm{C}$ overnight and protein $\mathrm{A} / \mathrm{G}$ sepharose (Santa Cruz, CA, USA) beads were then added for $3 \mathrm{~h}$. The beads were collected and washed with lysis buffer for 3 times. Immunoprecipitated proteins were resolved by SDS-PAGE and blotted with the indicated antibodies.

\subsection{Statistical Analysis}

All data are presented as mean \pm SEM. Statistical significance was tested using Student's t test, one-way ANOVA, and Chi-square test in software SPSS 16.0. A p value of $<0.05$ was considered statistically significant.

\subsection{Supplement Information}

Supplemental Information includes Supplemental Experimental Procedures. 


\section{Results}

\subsection{EGFR Interacts with TfR1 in Cytosol}

To understand whether EGFR could directly regulate TfR1-mediated iron homeostasis, we examined the reciprocal interaction between EGFR and TfR1. We chose three NSCLC lines with different EGFR forms to detect the interaction: A549 (wild-type EGFR), PC-9 (in-frame deletion in exon 19 around codons $746-750, \Delta 746-750$ ) and $\mathrm{H} 1975$ (threonine-to-methionine substitution at amino acid position 790, T790M). Firstly, we performed co-immunoprecipitation assay in A549, PC-9, H1975, and 293T cells co-transfected with HA-tagged EGFR (at C-terminus) and Flag-tagged TfR1 (at $\mathrm{N}$-terminus). The results indicated that there was a protein-protein interaction between EGFR and TfR1 (Figure 1A and 1B). To further confirm the binding of EGFR mutants to TfR1, we made a series of EGFR constructs with mutations as, $\Delta 746-750$, single base substitution in exon 21 (L858R) and T790M for immunoprecipitation analysis. We found that EGFR activation mutants could bind to TfR1 as wild-type EGFR did (Figure 1C). Additionally, we examined the cellular localization of EGFR and TfR1 by immunofluorescent labeling. Interestingly, in A549 and PC-9 cells, we observed a colocalization of EGFR and TfR1 in the cytoplasm but not in the cell surface (Figure 1D). Then, we extracted the components of cell surface membrane and cytoplasm to perform immunoprecipitation assay, respectively. The results further proved 
that their interaction only occurred in the cytosol (Figure 1E).

\subsection{EGFR Interacts with TfR1 in a Kinase-Dependent Manner}

Intriguingly, we found that kinase-deficient mutant EGFR (K745R) weakly bound to TfR1, which suggested that EGFR kinase activity was possibly important for the interaction between EGFR and TfR1. To test this hypothesis, we applied two specific tyrosine kinase inhibitors (TKIs), erlotinib and gefitinib, to inhibit EGFR kinase activity in sensitive (PC-9 and HCC827) and resistant (H1975) lung cancer cell lines. After the addition of erlotinib or gefitinib for $16 \mathrm{~h}$, the interaction between EGFR and TfR1 was obviously suppressed in both PC-9 and HCC827 but not in H1975 cells (Figure 2A and 2B). To further validate the conclusion, we tested their interaction in A549 cells. As shown in Figure 2C, inactivated EGFR were not immunoprecipitated with TfR1 when the cells were cultured in the serum-free medium. In contrast, upon EGF stimulation for $16 \mathrm{~h}$, EGFR was activated and interacted with TfR1, which was abrogated by erlotinib. In addition, we also observed that EGFR were colocalized with TfR1 after EGF stimulation, whereas this colocalization was not detected without EGF stimulation or in the treatment of erlotinib. Together, our data indicate that the interaction between EGFR and TfR1 depends on tyrosine kinase activity of EGFR.

Previous studies have shown that TfR 1 can be phosphorylated by some tyrosine kinases (14).We next tested whether TfR1 is a substrate of EGFR. 
The results showed that suppression of EGFR kinase activity did not affect tyrosine phosphorylation of TfR1 (Figure 2A), which implicated that EGFR could not mediate tyrosine phosphorylation of TfR1.

\subsection{EGFR Kinase Activity Maintains Cell Surface TfR1 Expression}

Interestingly, we found that TfR1 subcellular localization was changed along with EGFR activation (Figure 2D), which promoted us to further investigate whether EGFR regulates TfR1 distribution. Firstly, we detected the change of TfR 1 expression on cell surface by fluorescence activated cell sorting (FACS). The representative results showed that the protein level of TfR1 at cell surface was significantly reduced by TKIs in PC-9 cells (Figure 3A and $3 \mathrm{~B}$ ). Consistently, the similar results were observed via fluorescence microscopy (Figure 3C). Additionally, once EGFR was activated by EGF stimulation, an obvious increase of cell surface TfR1 expression was detected in A549 cells (Figure 3D). To validate the conclusion in another way, we established A549 cell lines stably overexpressing vector, wild-type EGFR or EGFR mutants (K745R, $\Delta 746-750)$ which had different tyrosine kinase activities. We observed that while activated EGFR (wild-type EGFR and $\Delta$ 746-750) markedly elevated the cell surface expression of TfR1, inactivated EGFR (K745R) did not bring about significant influence when compared with the group of vector (Figure 3D). 
It is noteworthy that the total TfR1 protein level was not changed regardless of EGFR kinase activity was inhibited or activated (Figure 2A and 2C) within $16 \mathrm{~h}$, which implied that EGFR did not alter TfR1 expression within a short time scale. It was also proved by us that the addition of TKIs did not result in significant alteration of TfR1 mRNA level after $16 \mathrm{~h}$ (Figure S1A). Consistent with these results, we found TfR1 expression level in A549 cell lines stably overexpressing different EGFR forms was not changed (Figure S1B). Together, these data suggest that the activation of EGFR is important for maintaining cell surface TfR1 expression.

\subsection{EGFR Kinase Activity Regulates the Cytoplasm Distribution of TfR1}

We next explored whether EGFR kinase activity also modulated TfR1 distribution in cytoplasm. For this purpose, we separately extracted the components of cell membrane and cytosol to detect TfR1 protein expression by western blot. As shown in Figure 4A, while cell surface TfR1 expression was significantly down-regulated by TKIs after $16 \mathrm{~h}$, its expression in cytosol was up-regulated. Moreover, we further detected the colocalization of TfR1 with Rab5 (an early endosome marker) or LAMP1 (a late endosome/lysosome marker) by immunofluorescence. It was observed that more TfR1 was colocalized with Rab5 and LAMP1 when EGFR kinase activity was inhibited by TKls (Figure 4B and $4 \mathrm{C}$ ), which was compatible with the increase of TfR1 
protein expression in cytosol. This result also suggested that EGFR inactivation caused more protein degradation of TfR1 through lysosomal trafficking pathway. Indeed, we found obvious reduction of TfR1 protein level under the treatment of TKIs for 48 and $72 \mathrm{~h}$ (Figure 4D), which implicated that the regulation of TfR1 distribution by EGFR affected TfR1 protein expression at a long time scale.

Together, these results demonstrate that EGFR kinase activity can modulate TfR1 distribution to maintain high protein expression of TfR1.

\subsection{EGFR Kinase Activity Affects Cellular Iron Homeostasis}

TfR1 presented on the surface of the cell membrane can bind to iron loaded Tf and mediate iron uptake into cells via endocytosis. Thus, although the above results suggest EGFR activation promoted cell surface TfR1 expression, it was unclear whether this resulted in a subsequent increase in iron uptake. Therefore, we investigated the effect of EGFR kinase activity on iron import by examining Tf uptake. The internalized transferrin was measured by Tf-pHrodo ${ }^{\mathrm{TM}}$ Red conjugate. In PC-9 cells, the addition of TKI markedly reduced the internalized $\operatorname{Tf}$ (Figure 5A). We further confirmed this results by examining $\mathrm{Tf}$ internalization rate using Tf-Alexa 488. EGFR-TKIs treatment resulted in a $30 \%$ decrease in the internalization rate of $\mathrm{Tf}$ in PC-9 cells (Figure 5B).Vice versa, EGF-stimulation caused a 1.5 fold increase in the internalization rate for $\mathrm{Tf}$ in A549 cells (Figures 5C). Then we examined the 
iron concentrations in TKI-treated cells and found it was also lower than that in DMSO-treated cells (Figure 5D). In A549 cells that transfected with different EGFR forms, higher iron concentration was observed in cells overexpressing EGFR active mutation ( $\Delta 746-750)$ than that in the other cells (Figure $5 E$ ).

Together, these data suggest that EGFR can affect cellular iron homeostasis by regulating the distribution of TfR1.

\subsection{Non-Tf-Bound Iron Partially Rescues the Growth Inhibition and Cell Cycle Arrest Caused by EGFR Inactivation}

It has been widely reported that down-regulation of EGFR activity could induce cell cycle arrest and apoptosis $(15,16)$. To demonstrate the importance of TfR1-dependent iron uptake pathway in EGFR-promoted cancer proliferation, we tested whether supplementation of iron could rescue the cell cycle arrest and growth inhibition caused by TKIs in PC-9 cells. As shown in Figure $6 A$ and $6 B$, TKIs significantly led to the cell cycle arrest in $G 1 / S$ phase which was consistent with the previous reports. Notably, supplementation of ferric citrate (non-Tf-bound iron) could partially reverse the effects of TKIs. Moreover, addition of ferric citrate also partially rescued the deficiency of cancer cell growth resulting from TKIs in CCK8 and colony formation assay (Figure 6C and 6D).

Together, these data reinforces the critical roles of EGFR-mediated iron assimilation in facilitating cancer growth and survival. 


\subsection{EGFR activation is Positively Correlated with Membrane TfR1 and Iron Expression in NSCLC}

To understand the significance of TfR1 regulation mediated by activated EGFR, we performed the experiments in a subcutaneous xenograft model. The results showed that the iron content and growth rate of tumors overexpressing EGFR active mutant ( $\Delta 746-750)$, which had high-level EGFR phosphorylation, were higher than those with low-level EGFR phosphorylation (Figure 7A, 7B and 7C). These observations suggest that EGFR activation is positively correlated with intracellular iron level and tumor growth of lung cancer. Next,

We further carried out immunohistochemistry to examine the correlation among EGFR activation, TfR1 protein expression (membrane distribution) and iron levels in clinical samples. We observed that phosphorylation of EGFR Y1092 was significantly associated with TfR1 and iron expression in tumor tissues (Figure 7D). It was worth noting that the membrane TfR1 protein expression was markedly elevated in the samples with high EGFR phosphorylation (Figure 7E), which suggested that activated EGFR maintained TfR1 distribution on cell surface of lung cancer. Furthermore, increased iron levels were detected in the samples which had high levels of EGFR Y1092 phosphorylation (Figure 7E).

Together, these findings reveal that EGFR activation is positively related to membrane TfR1 expression and intracellular iron levels in NSCLC. 


\section{Discussion}

Our study proves that EGFR activation enhances its interaction with TfR1 and increases cell surface TfR1 expression (Figure 1, 2 and 3). It has been reported that EGFR localizes in the lipid raft fraction while TfR1 is a non-lipid raft plasma membrane marker (17). Consistent with this, we find that the interaction between EGFR and TfR1 only occurs in cytosol (Figure 1A and 1E). It has also been reported that EGFR and TfR1 both localizes selectively to TfR1-containing coated-pits (CCP) and -vesicles (CCV) $(18,19)$. Another research group has proposed a model that, in the case of RTKs, tyrosine phosphorylation of TTP (Transferrin receptor Trafficking Protein, a SH3-containing protein) and/or dynamin, might prevent their interaction, thus excluding TTP from RTK-containing pits (20), this is conflict with our results that EGFR activation enhances its interaction with TfR1. Thus, it will be important for future work to elucidate the exact cytoplasmic organelle where they interact with each other.

Iron-regulatory proteins directly affect intracellular iron content through IRP1/2 system. It increases the expression levels of proteins associated with iron uptake when intracellular iron levels are low and vice versa (21). Our results demonstrate that EGFR activation elevates cell surface TfR1 expression within $16 \mathrm{~h}$ while total TfR1 expression is unchanged (Figure 3D and $3 E$ ), which suggests that EGFR does not regulate TfR1 through the IRP1/2 system within a short time scale. The conclusion is further validated by 
the observation of unchanged mRNA expression of TfR1 after treatment of TKls for $16 \mathrm{~h}$ (Figure S1A). Intriguingly, we find that TfR1 expression level is down-regulated by TKIs after 48 or $72 \mathrm{~h}$ (Figure 4D). The reason can be attributed to the enhanced colocalization of TfR1 with lysosome. Taken together, we propose a model that EGFR kinase activity not only elevates TfR1 membrane distribution but also inhibits TfR1 protein lysosomal degradation, thus safely guaranteeing high Tf internalization in cancer. Our study shows that EGFR tyrosine kinase activity regulates cellular iron uptake. It has been well known that accumulation of sufficient iron is essential for cancer cells, because most enzymes responsible for DNA synthesis and cell cycle progression require a continual supply of iron. Cyclin-dependent kinase 4 (CDK4) and CDK6, two proteins that regulate $\mathrm{G} 1 / \mathrm{S}$ progression, are modulated by iron levels (22). We observe that the inhibition of EGFR tyrosine kinase activity results in reduced iron uptake in NSCLC cells (Figure 5D). Consistently, EGFR active mutant ( $\Delta 746-750)$ which had high kinase activity led to significant accumulation of intracellular iron (Figure 5E). Importantly, we further demonstrate that supplementation of non-Tf-bound iron can partially rescue deficiency of cancer cell growth resulting from TKls (Figure 6). Collectively, these data indicate that EGFR-mediated iron uptake is important for cancer growth and survival.

One important evidence in this study is that there is a positive correlation among EGFR activation, membrane TfR1 protein expression and intracellular 
iron levels in patient samples. Importantly, this observation further supports the clinical significance of our finding that EGFR directly modulates iron uptake through TfR1 distribution. However, we fail to find that high level of TfR1 or iron is associated with the short survival of NSCLC patients (Figure S2A and S2B). The reason may be that cellular iron level is easily changed by diverse factors due to complicated regulatory system. For example, it has been reported that iron in cancer can be affected by inflammation and acute-phase response (23, 24).

In summary, the present study identified EGFR as a novel regulatory protein for TfR1, which plays an important role in maintaining high level of cellular iron in cancer. Our results provide new insight into the mechanism that EGFR exerts its oncogenic effects by redistributing TfR 1 to regulate iron uptake.

\section{Acknowledgements}

This study was supported by National Science Foundation of China (NSFC grant 81472569 and 81301819 ), the project of Shanghai Science and Technology Committee (Grant No. 1541196100), the project of Shanghai Municipal Health Bureau (Grant No. 20134043), and the Grant-in-Aid for Young Scientists Foundation of Shanghai Cancer Institute (SB14-04).

\section{Conflicts of interest: none}




\section{References}

1 Arredondo, M. and Nunez, M.T. (2005) Iron and copper metabolism. Molecular aspects of medicine, 26, 313-327.

2 Whitnall, M., Howard, J., Ponka, P. and Richardson, D.R. (2006) A class of iron chelators with a wide spectrum of potent antitumor activity that overcomes resistance to chemotherapeutics. Proceedings of the National Academy of Sciences of the United States of America, 103, 14901-14906.

3 Torti, S.V. and Torti, F.M. (2011) Ironing out cancer. Cancer research, 71, 1511-1514.

4 Richardson, D.R. and Ponka, P. (1997) The molecular mechanisms of the metabolism and transport of iron in normal and neoplastic cells. Biochimica et biophysica acta, 1331, 1-40.

5 Lane, D.J., Bae, D.H., Merlot, A.M., Sahni, S. and Richardson, D.R. (2015) Duodenal cytochrome b (DCYTB) in iron metabolism: an update on function and regulation. Nutrients, 7, 2274-2296.

6 Hentze, M.W., Muckenthaler, M.U. and Andrews, N.C. (2004) Balancing acts: molecular control of mammalian iron metabolism. Cell, 117, 285-297.

7 Levy, J.E., Jin, O., Fujiwara, Y., Kuo, F. and Andrews, N.C. (1999) Transferrin receptor is necessary for development of erythrocytes and the nervous system. Nature genetics, 21, 396-399.

8 Xiong, W., Wang, L. and Yu, F. (2014) Regulation of cellular iron metabolism and its implications in lung cancer progression. Medical oncology, 31, 28.

9 Chanvorachote, P. and Luanpitpong, S. (2016) Iron induces cancer stem cells and aggressive phenotypes in human lung cancer cells. American journal of physiology. Cell physiology, 310, C728-739.

10 Zhang, C. and Zhang, F. (2015) Iron homeostasis and tumorigenesis: molecular mechanisms and therapeutic opportunities. Protein \& cell, 6, 88-100.

11 Walker, R.A. and Day, S.J. (1986) Transferrin receptor expression in non-malignant and malignant human breast tissue. The Journal of pathology, 148, 217-224.

12 Soyer, H.P., Smolle, J., Torne, R. and Kerl, H. (1987) Transferrin receptor expression in normal skin and in various cutaneous tumors. Journal of cutaneous pathology, 14, 1-5.

13 Yarden, Y. and Sliwkowski, M.X. (2001) Untangling the ErbB signalling network. Nature reviews. Molecular cell biology, 2, 127-137.

14 Jian, J., Yang, Q. and Huang, X. (2011) Src regulates $\operatorname{Tyr}(20)$ phosphorylation of transferrin receptor-1 and potentiates breast cancer cell survival. The Journal of biological chemistry, 286, 35708-35715.

15 Park, E.J., Min, H.Y., Chung, H.J., Hong, J.Y., Kang, Y.J., Hung, T.M., Youn, U.J., Kim, Y.S., Bae, K., Kang, S.S. et al. (2009) Down-regulation of c-Src/EGFR-mediated signaling activation is involved in the honokiol-induced cell cycle arrest and apoptosis in MDA-MB-231 human breast cancer cells. Cancer letters, 277, 133-140.

16 Lui, V.W. and Grandis, J.R. (2002) EGFR-mediated cell cycle regulation. Anticancer research, 22, 1-11.

17 Pike, L.J. (2005) Growth factor receptors, lipid rafts and caveolae: an evolving story. Biochimica et biophysica acta, 1746, 260-273.

18 Warren, R.A., Green, F.A., Stenberg, P.E. and Enns, C.A. (1998) Distinct saturable pathways for the endocytosis of different tyrosine motifs. The Journal of biological chemistry, 273, 17056-17063. 
19 Warren, R.A., Green, F.A. and Enns, C.A. (1997) Saturation of the endocytic pathway for the transferrin receptor does not affect the endocytosis of the epidermal growth factor receptor. The Journal of biological chemistry, 272, 2116-2121.

20 Tosoni, D., Puri, C., Confalonieri, S., Salcini, A.E., De Camilli, P., Tacchetti, C. and Di Fiore, P.P. (2005) TTP specifically regulates the internalization of the transferrin receptor. Cell, 123, 875-888.

21 Torti, S.V. and Torti, F.M. (2013) Iron and cancer: more ore to be mined. Nature reviews. Cancer, 13, 342-355.

22 Malumbres, M. and Barbacid, M. (2009) Cell cycle, CDKs and cancer: a changing paradigm. Nature reviews. Cancer, 9, 153-166.

23 Kukulj, S., Jaganjac, M., Boranic, M., Krizanac, S., Santic, Z. and Poljak-Blazi, M. (2010) Altered iron metabolism, inflammation, transferrin receptors, and ferritin expression in non-small-cell lung cancer. Medical oncology, 27, 268-277.

24 Sattar, N., Scott, H.R., McMillan, D.C., Talwar, D., O'Reilly, D.S. and Fell, G.S. (1997) Acute-phase reactants and plasma trace element concentrations in non-small cell lung cancer patients and controls. Nutrition and cancer, 28, 308-312. 


\section{FIGURE CAPTIONS}

\subsection{Figure 1. EGFR Interacts with TfR1 in Cytosol.}

(A) The cell lysates from A549, PC-9 and H1975 were immunoprecipitated with anti-TfR1 antibody or anti-EGFR antibody, and then subjected to immnuoblotting analysis.

(B) The cell lysates from 293T cells exogenously expressing EGFR-HA (at C-terminus) and Flag-TfR1 (at N-terminus) were subjected to immunoprecipitation (IP) and immnuoblotting (IB) with the indicated antibodies. WCL, whole cell lysates.

(C) Lysates from 293T cells ectopically co-expressing Flag-TfR1 and wide-type or different mutations of EGFR-HA were subjected to IP/IB with the indicated antibodies.

(D) Representative images of TfR1 (green), EGFR (red) and DAPI (blue) in A549 and PC-9 cells by confocal microscopy. Scale bar represents $20 \mu \mathrm{M}$.

(E) The protein extracts from cell membrane and cytosol of PC-9 cell were subjected to IP/IB with the indicated antibodies. HSP90 and pan-Cadherin were used as cytoplasmic marker and plasma membrane marker, respectively.

\subsection{Figure 2. EGFR Kinase Activity Is Essential for the Interaction between EGFR and TfR1.}

(A) PC-9 and HCC827 cells were treated with DMSO, erlotinib $(1 \mu \mathrm{M})$ or gefitinib $(1 \mu \mathrm{M})$ for $16 \mathrm{~h}$, then lysed and immunoprecipitated with anti-EGFR 
antibody. The precipitated proteins were subjected to immnuoblotting analysis. (B) $\mathrm{H} 1975$ cells were treated with DMSO, erlotinib $(1 \mu \mathrm{M})$ or gefitinib $(1 \mu \mathrm{M})$ for $16 \mathrm{~h}$, the interaction between EGFR and TfR1 was examined by the indicated antibodies in IP/IB analysis.

(C) Lysates from A549 cells cultured in serum-free medium, serum-free medium plus EGF (50 ng/ml, $16 \mathrm{~h})$, or serum-free medium plus EGF $(50 \mathrm{ng} / \mathrm{ml}$, $16 \mathrm{~h})$ and erlotinib $(1 \mu \mathrm{M}, 16 \mathrm{~h})$ were immunoprecipitated with anti-EGFR antibody, then the precipitated proteins were subjected to IP and blotted with the indicated antibodies.

(D) Representative images of colocalization between TfR1 and EGFR in A549 cells cultured in serum-free medium, serum-free medium plus EGF $(50 \mathrm{ng} / \mathrm{ml}$, $16 \mathrm{~h})$, or serum-free medium plus EGF $(50 \mathrm{ng} / \mathrm{ml}, 16 \mathrm{~h})$ and erlotinib $(1 \mu \mathrm{M}$, 16h).

\subsection{Figure 3. EGFR Kinase Activity Maintains Cell Surface TfR1 Expression.}

(A) Cell surface TfR1 expression was detected in unpermeabilized PC-9 cells using anti-TfR 1 antibody by flow cytometry. Cells were either left unstained (red) or stained with the anti-TfR1 antibody.

(B) Quantitation of cell-surface TfR1 expression in conditions shown in (A). Bars are mean \pm SEM of triplicate samples. ${ }^{* * *} \mathrm{p}<0.001$.

(C) Representative images of cell surface TfR1 expression in unpermeabilized 
PC-9 cells treated with DMSO, erlotinib $(1 \mu \mathrm{M})$ or gefitinib $(1 \mu \mathrm{M})$ for $16 \mathrm{~h}(\mathrm{n}=$ 3). Bars are mean \pm SEM of triplicate samples. ${ }^{* * *} \mathrm{p}<0.001$.

(D) Cell surface TfR1 expression was detected in unpermeabilized A549 cells cultured in normal medium, serum-free medium, or serum-free medium plus EGF (50 ng/ml, $16 \mathrm{~h}$ ) using anti-TfR 1 antibody by flow cytometry. Cells were either stained with mouse IgG antibody as control or stained with the anti-TfR1 antibody $(n=3)$.

(E) Cell surface TfR1 expression was detected in unpermeabilized A549 cells ectopically expressing empty vector or indicted mutations of EGFR by flow cytometry. Cells were either stained with mouse IgG antibody as control or stained with the anti-TfR1 antibody $(n=3)$.

\subsection{Figure 4. Inhibition of EGFR Kinase Activity Leads to TfR1 Redistribution.}

(A) Lysates of cell membrane extract and the cytosol extract from PC-9 cells were immunoblotted with the indicated antibodies.

(B and C) Immunofluorescence of TfR1 and Rab5 stain in PC-9 cells treated with DMSO, erlotinib $(1 \mu M)$ or gefitinib $(1 \mu M)$ for $16 h(n=3)$. Scale bars represent $20 \mu \mathrm{M}$. Quantitation analyses are presented in the right panel, respectively. Bars are mean \pm SEM of triplicate samples. ${ }^{*} p<0.05,{ }^{* * *} p<$ 0.001 .

(D) Western blot analysis of TfR1 expression in PC-9 cells treated with 
erlotinib $(1 \mu \mathrm{M})$ or gefitinib $(1 \mu \mathrm{M})$ for indicated time.

\subsection{Figure 5. EGFR Kinase Activity Regulates Cellular Iron Homeostasis.}

(A) Cells were incubated with Tf-pHrodo ${ }^{\mathrm{TM}}$ Red-labelled Tf for $20 \mathrm{~min}$ at $37^{\circ} \mathrm{C}$. Then the internalization of Tf (red) was observed and quantified. Data represent the mean \pm SEM of three independent experiments. ${ }^{* * *} p<0.001$ compared with the control cells.

(B and C) Kinetics of internalization of Alexa488-Tf in PC-9 cells (B) and A549 (C) treated as indicated.

(D) Iron levels in PC-9 cells with erlotinib $(1 \mu \mathrm{M})$ or gefitinib $(1 \mu \mathrm{M})$ treatment for $16 \mathrm{~h}(\mathrm{n}=3)$, Bars are mean \pm SEM of triplicate samples. ${ }^{* *} p<0.01$ compared with control cells.

(E) Iron levels in A549 cells ectopically expressing empty vector or the indicted mutations of EGFR $(n=3)$. Bars are mean \pm SEM of triplicate samples. ${ }^{*} p<$ 0.05 .

\subsection{Figure 6. Complementation of the TKI-caused Cell Growth Inhibition with Non-Tf-Bound Iron Supplements.}

(A and B) FACS plots for each cell-cycle stage of PC-9 cells treated with erlotinib $(1 \mu \mathrm{M})$ or gefitinib $(1 \mu \mathrm{M})$ for $16 \mathrm{~h}$. The percentage of cells in $\mathrm{G} 1$ or $\mathrm{S}$ phase was analyzed by quantitation. Bars are mean \pm SEM of triplicate 
samples. ${ }^{* *} p<0.01$ and ${ }^{* * *} p<0.001$.

(C) Fe-citrate $(20 \mu \mathrm{M})$ supplement partially restore the cell growth inhibition in PC- 9 cells caused by TKIs. The rates of cell proliferation were examined by CCK-8 assay when cells were treated after $72 \mathrm{~h}$. Error bars represent SEM from three independent experiments. ${ }^{* *} P<0.01$ and ${ }^{* * *} P<0.001$, compared with the DMSO-treated group.

(D) The growth of A549 stable cell lines treated with erlotinib $(1 \mu \mathrm{M})$ or gefitinib $(1 \mu \mathrm{M})$ was determined by colony formation assay in the presence or absence of Fe-citrate $(20 \mu \mathrm{M})$. The pictures of developed colonies were shown after 14 days.

\subsection{Figure 7. Expression of Iron, Phospho-EGFR (Y1092) and TfR1 in Non-Small Cell Lung Cancer (NSCLC) Samples.}

(A)Tumor lysates of subcutaneously transplanted A549 cells $\left(5 \times 10^{6}\right)$ which stably overexpressing vector, wild-type EGFR or EGFR mutants (K745R, $\Delta 746-750)$ cells $(n=3)$ were blotted with the indicated antibodies.

(B) In vivo tumor iron content of subcutaneously transplanted A549 cells (5 x 106) which stably overexpressing vector, wild-type EGFR or EGFR mutants (K745R, $\Delta 746-750)$ cells $(\mathrm{n}=3)$.

(C) In vivo tumor growth of subcutaneously transplanted A549 cells $\left(5 \times 10^{6}\right)$ which stably overexpressing vector, wild-type EGFR or EGFR mutants (K745R, $\Delta 746-750)$ cells $(n=6)$. 
(D) Representative Iron, phospho-EGFR (Y1092), and TfR1 staining (H\&E) images in tissues microarray of the non-small cell lung cancer (NSCLC) samples. Case 1, low levels; Case 2, low levels. Scale bars represent $50 \mu \mathrm{M}$. (E) Correlation between phospho-EGFR (Y1092) and iron or membrane TfR1 protein expression in by immunohistochemical staining of NSCLC tissues microarray. The number of tissue samples and the percentage (\%) are shown. $p$ values were calculated by chi-square test. 
Figure 1
B

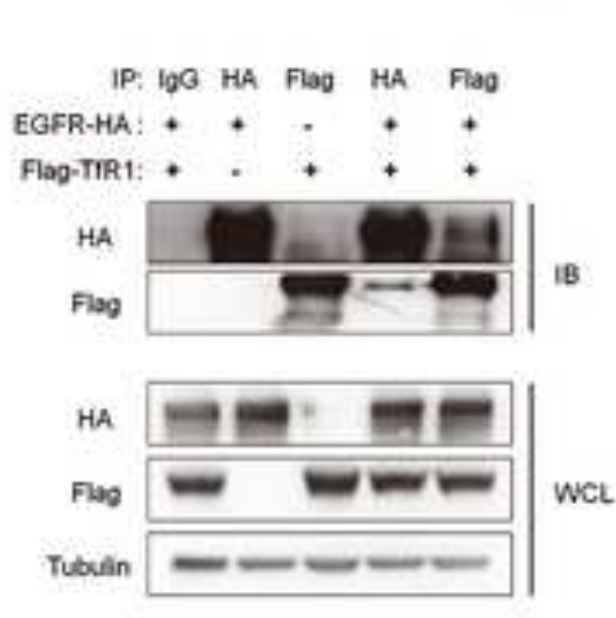

A

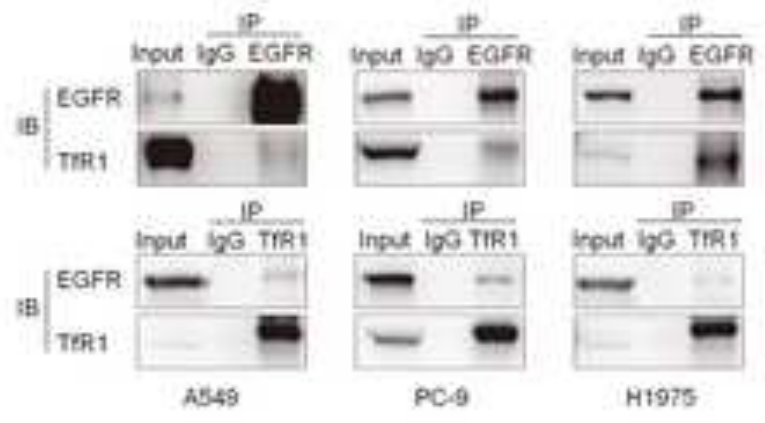

C
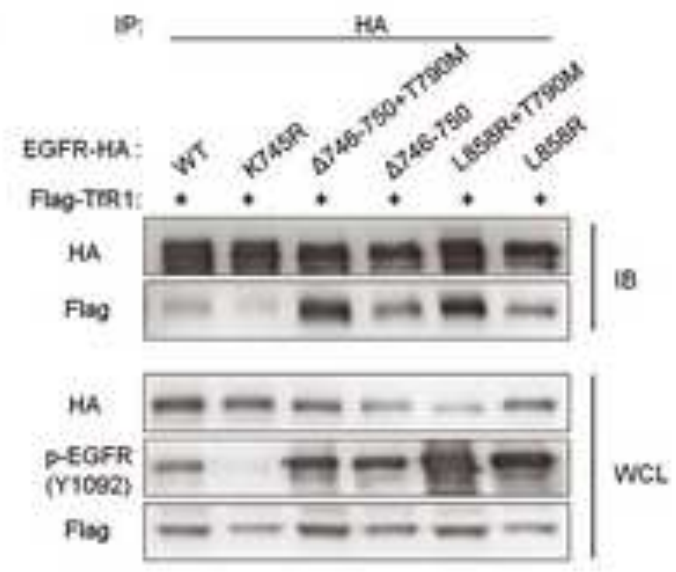

D

\begin{abstract}
DAPI
\end{abstract}

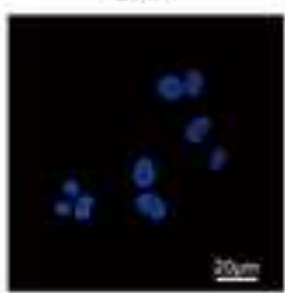

PC-9
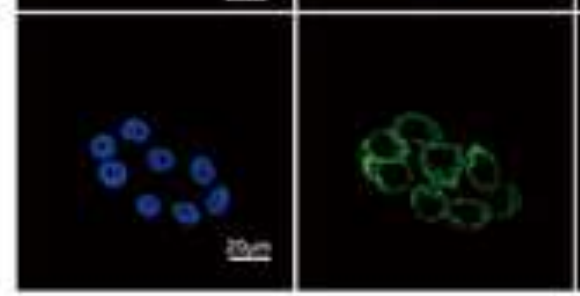

EGFR
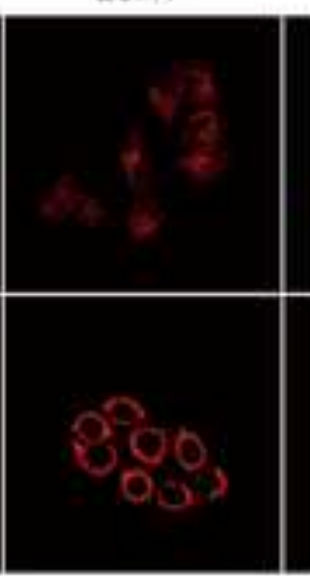

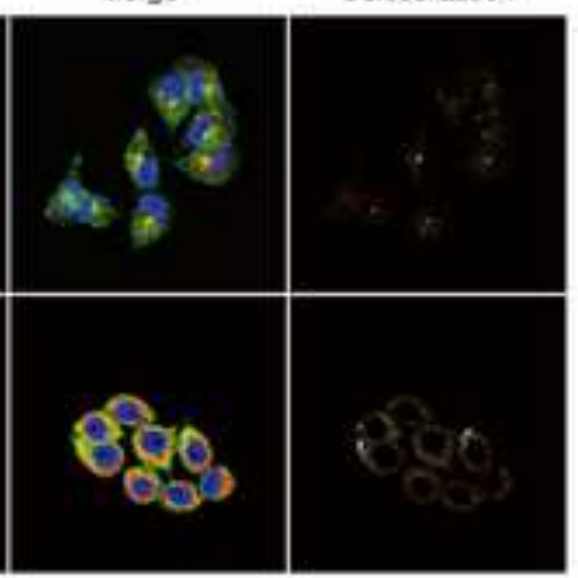

Colocalization

E

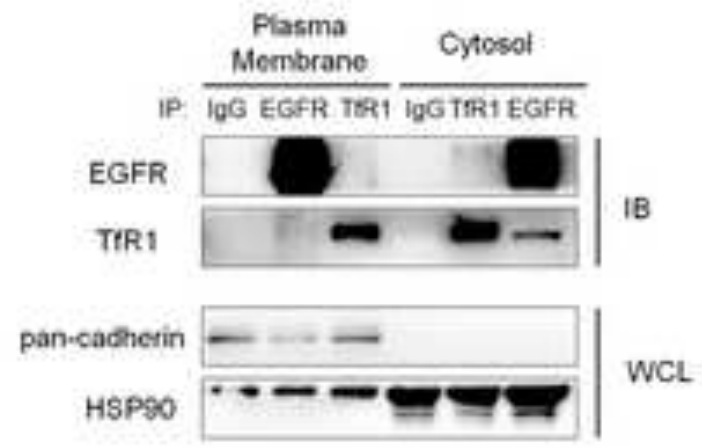


Figure 2

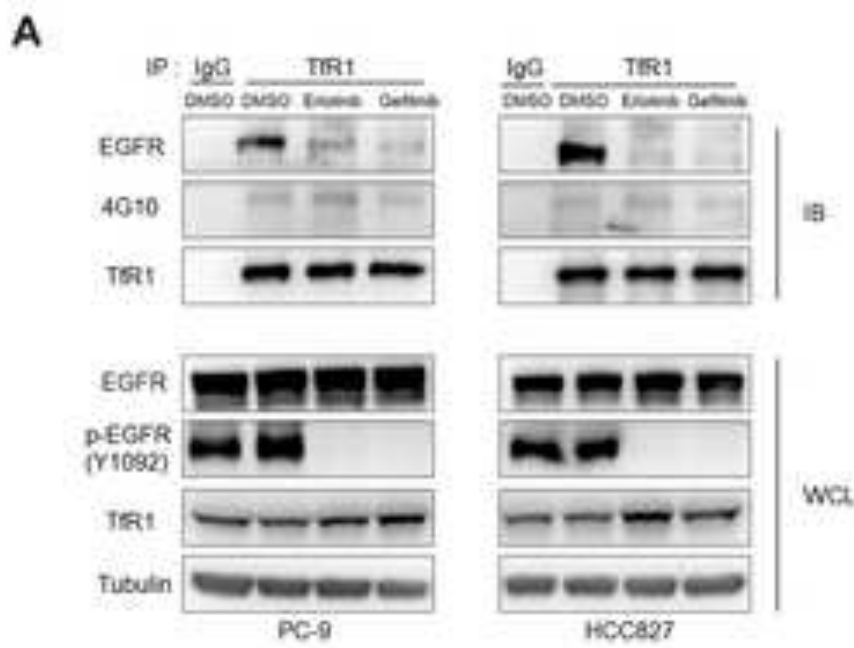

B

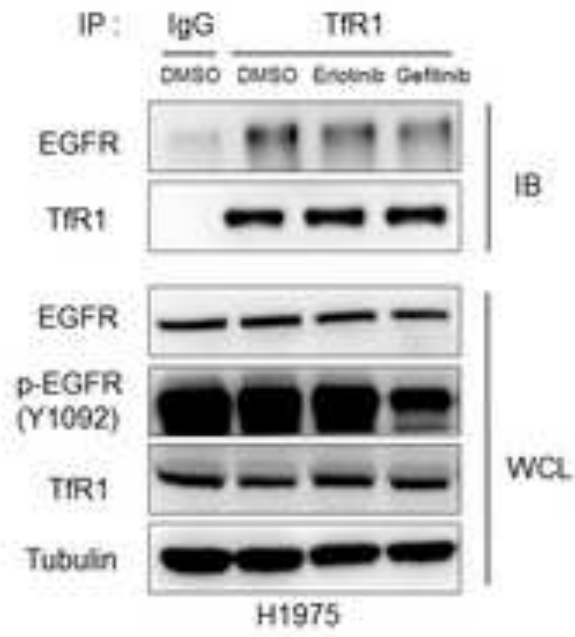

C

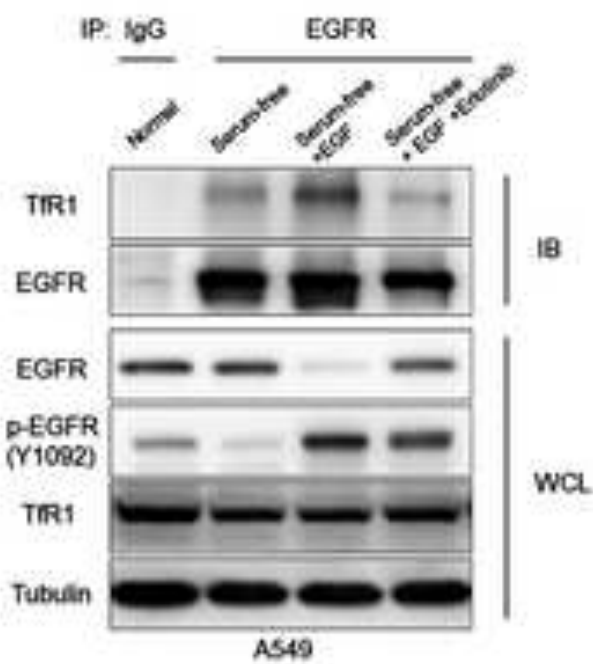

D

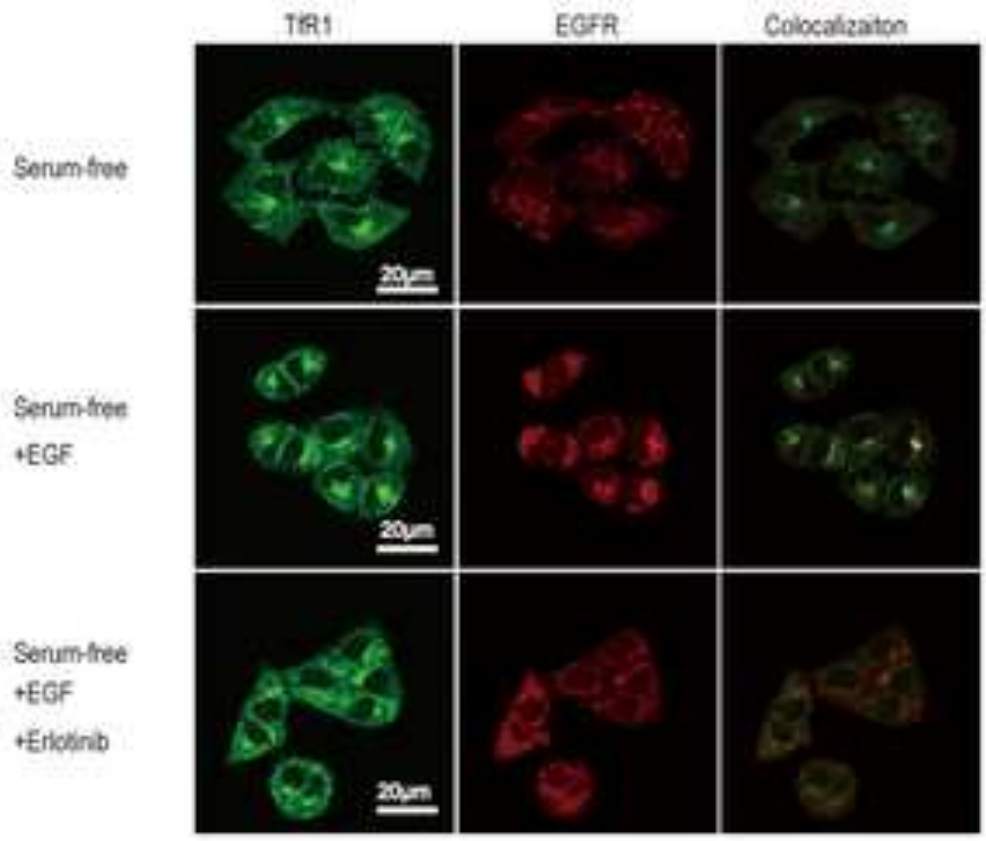


A

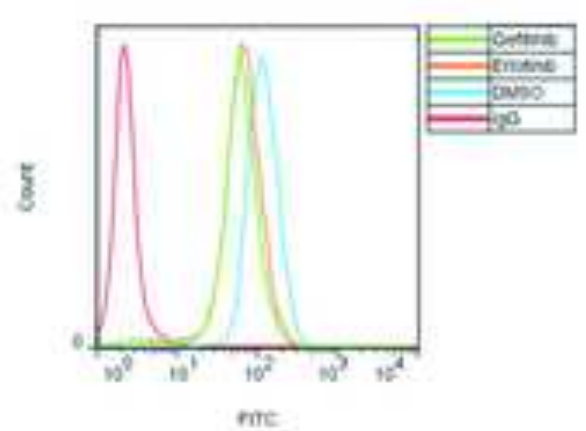

C

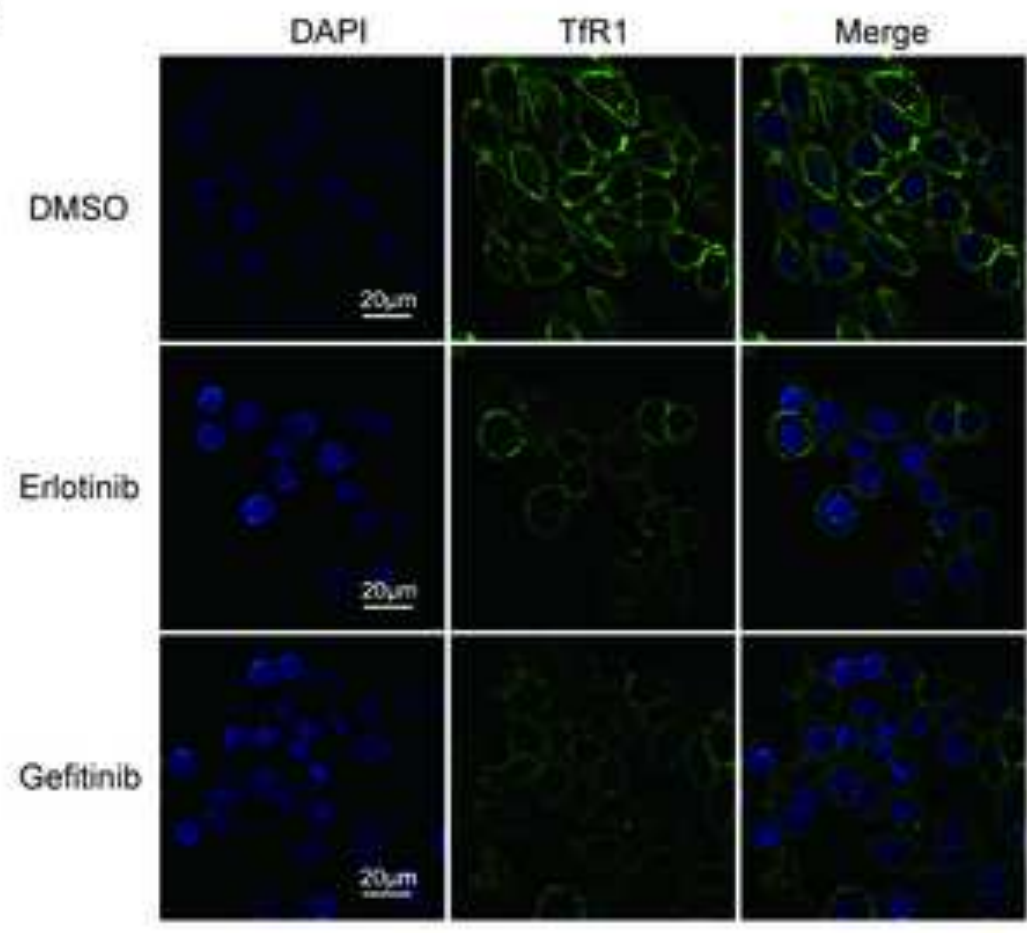

D

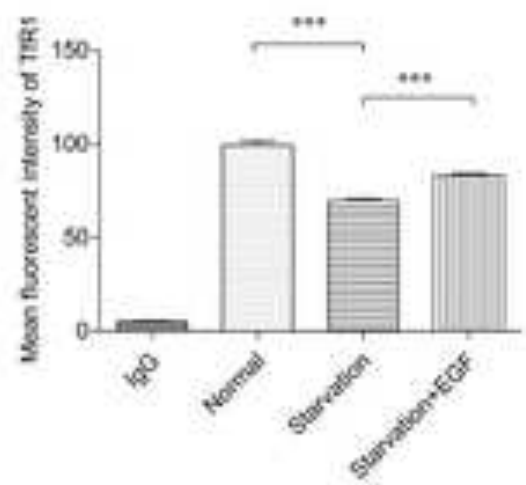

B
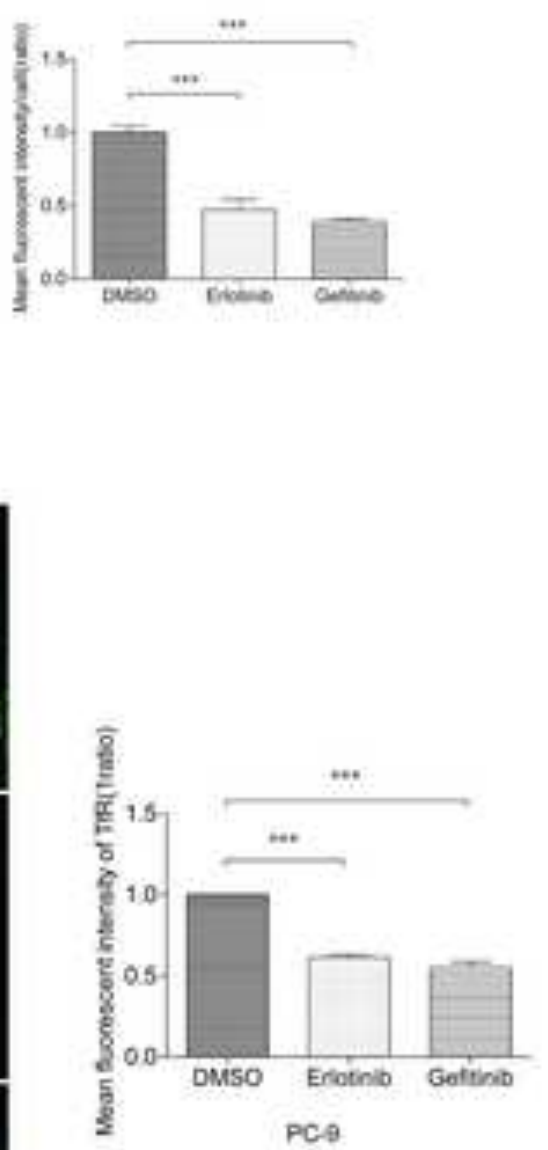

E

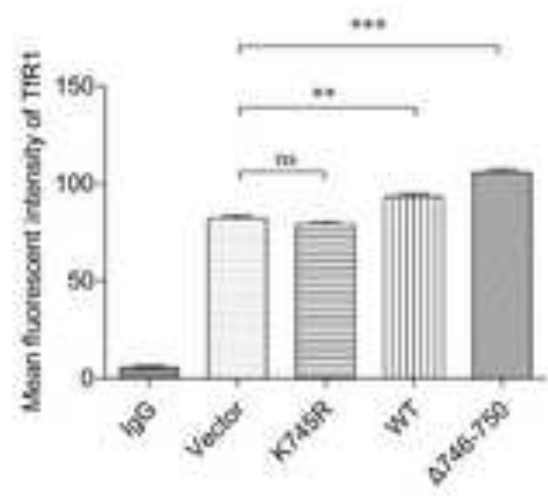


Figure 4

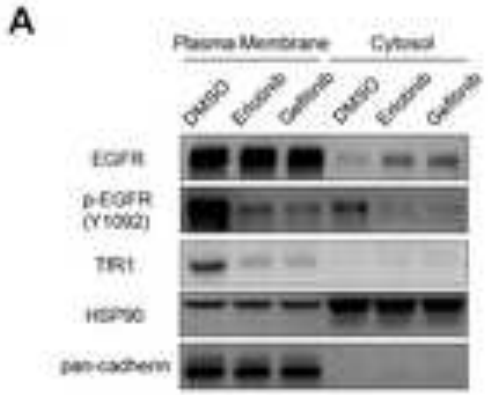

B
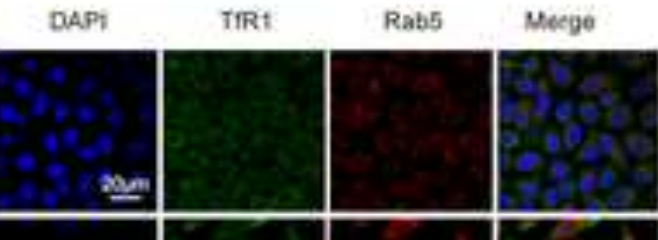

Erlotirib
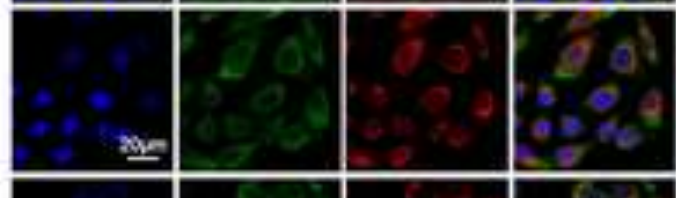

Geftino
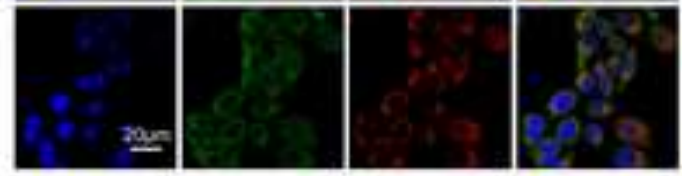

C
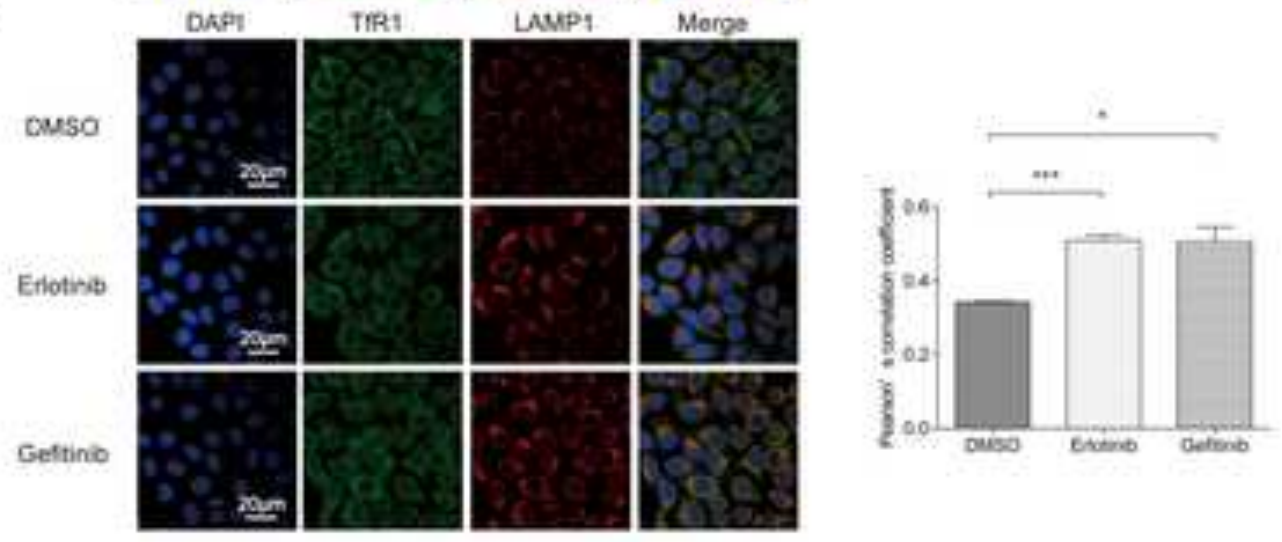

D
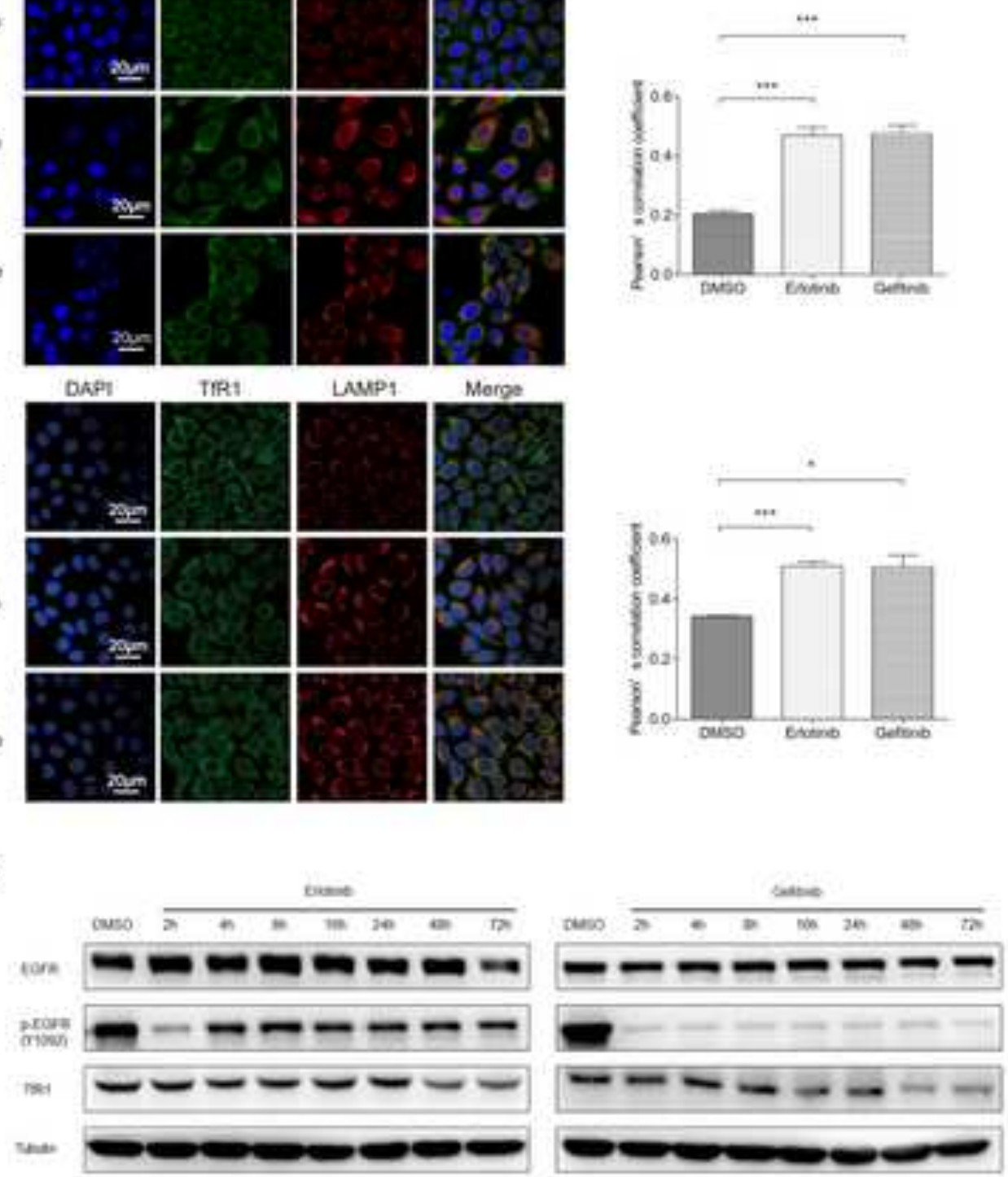
Figure 5

A

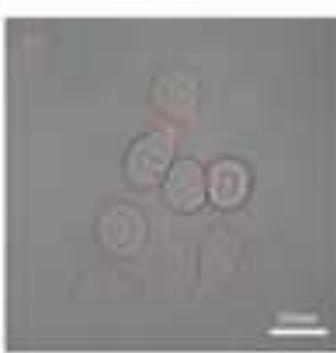

DMSO

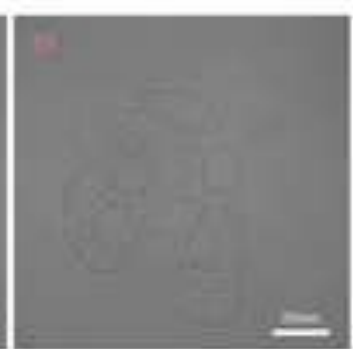

Erlotinith

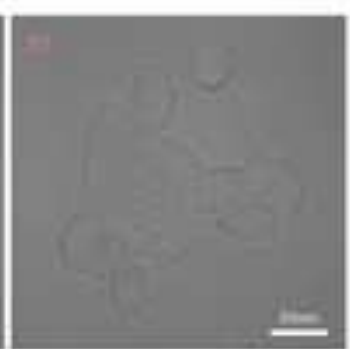

Gefitinib

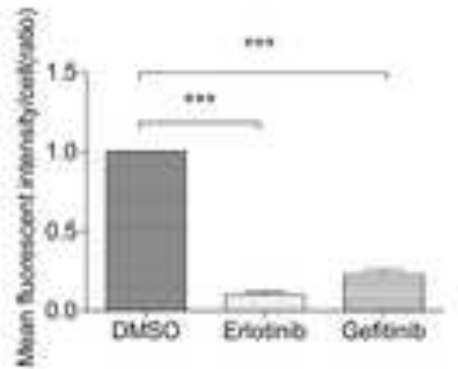

B

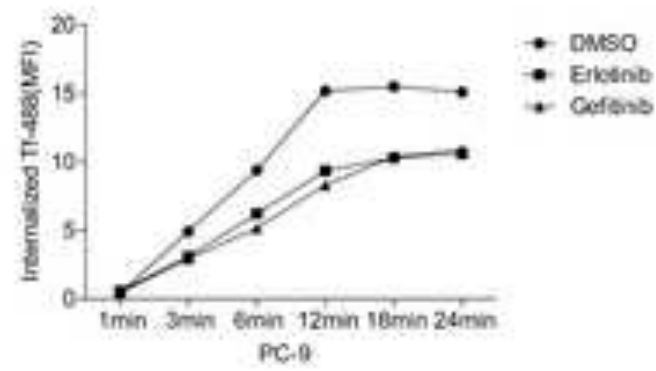

D

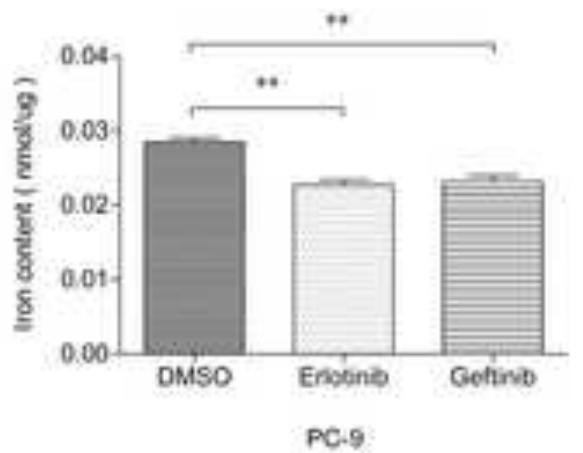

C

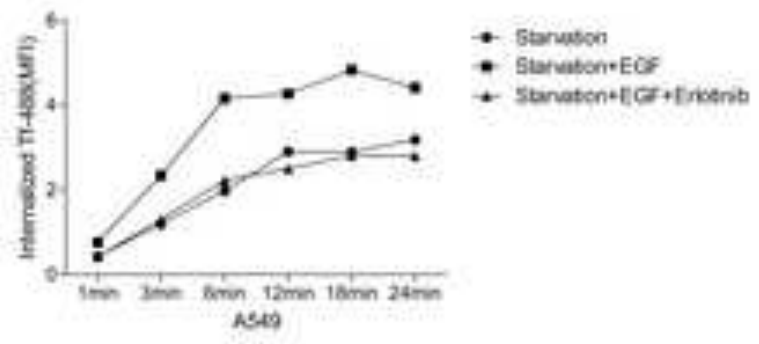

E

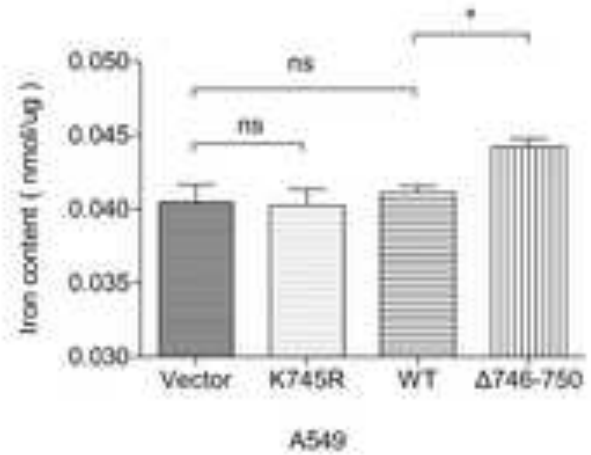


Figure(s)

Figure 6

A
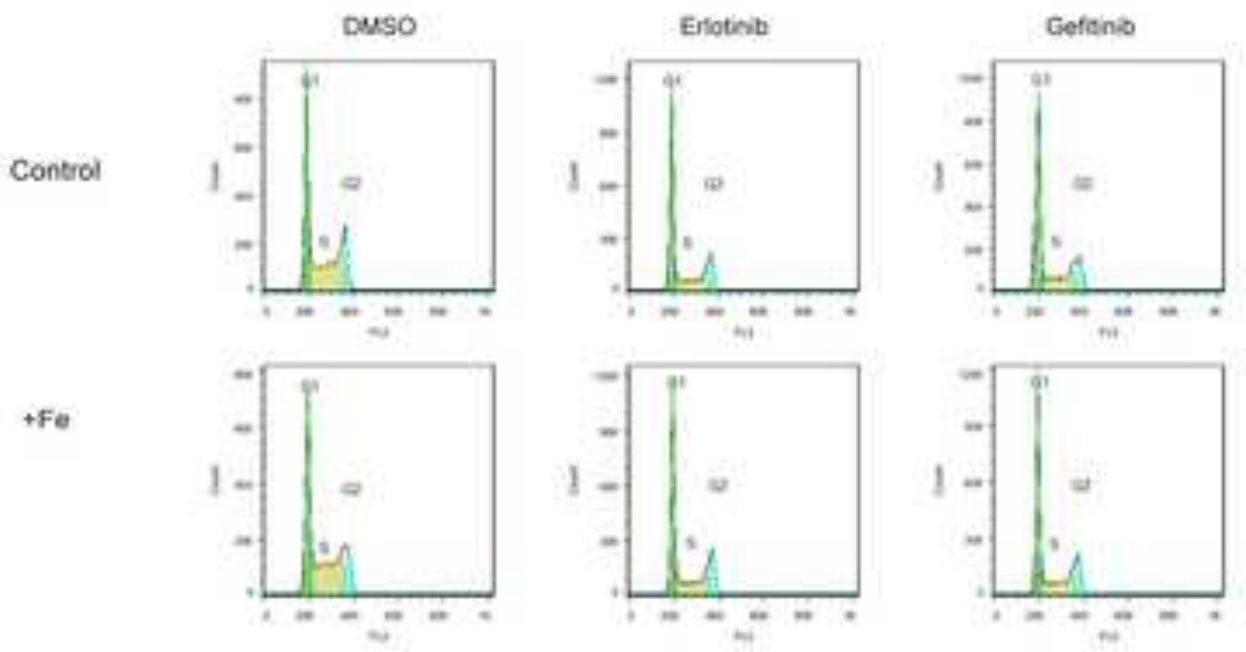

B
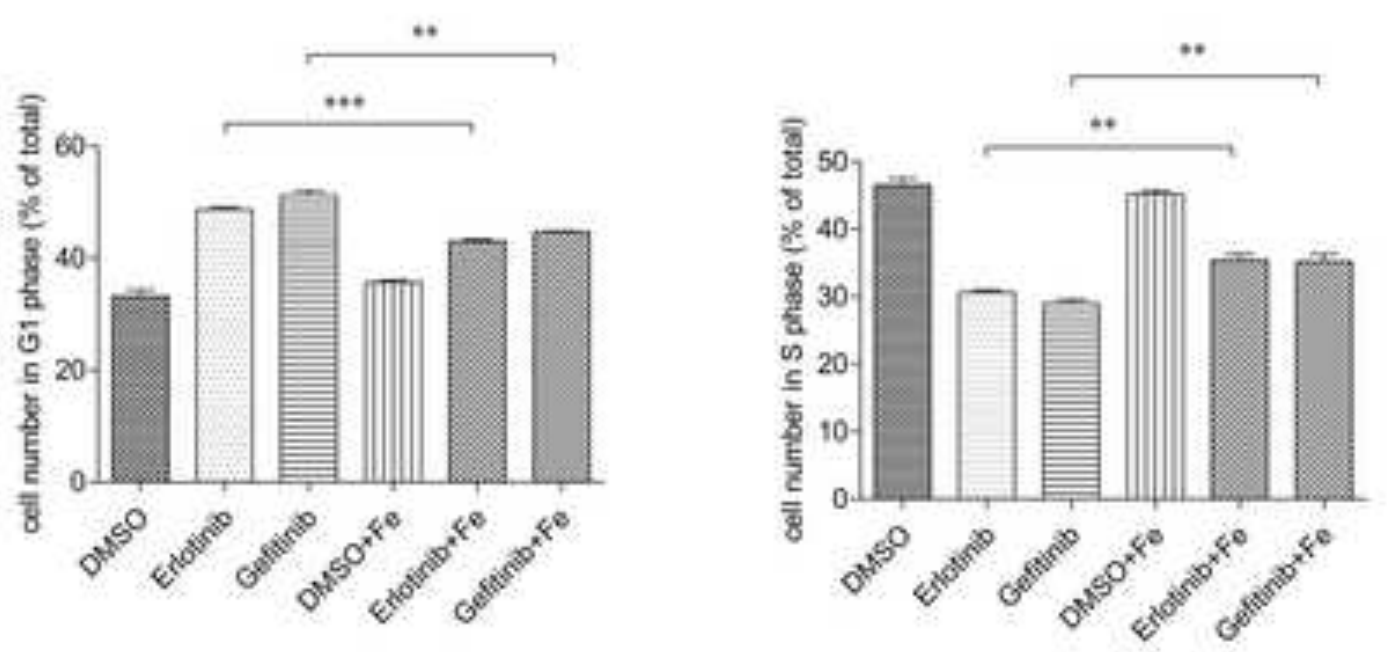

C

D
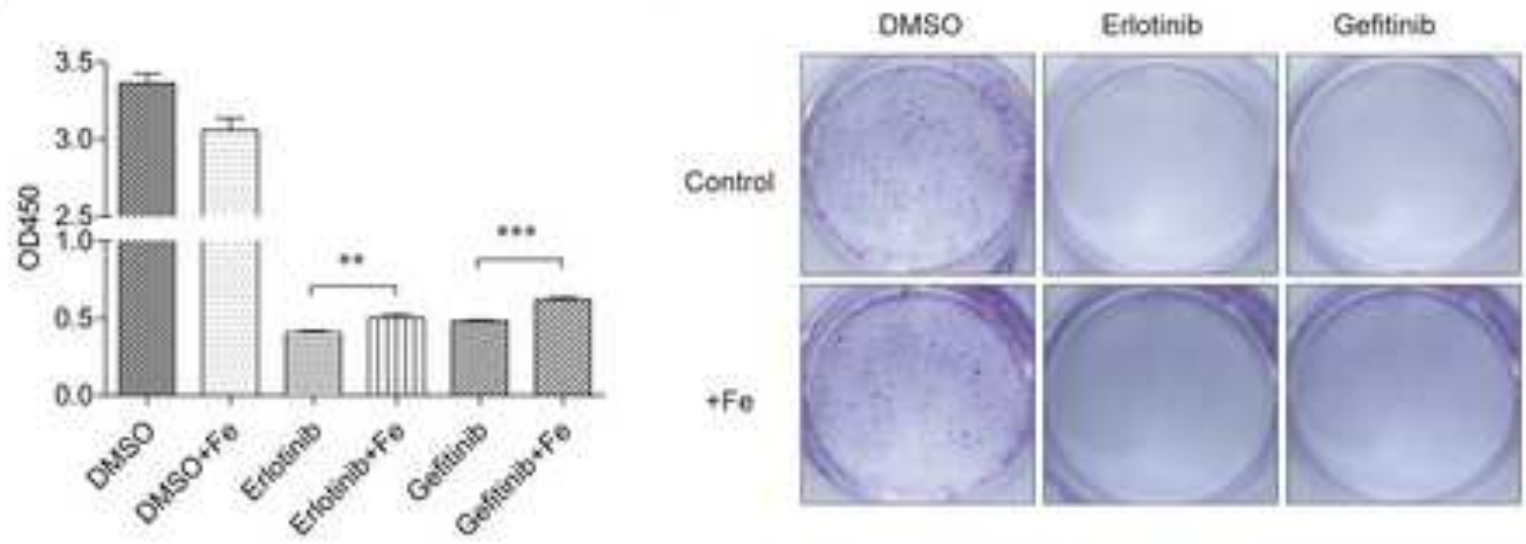


\section{Figure 7}

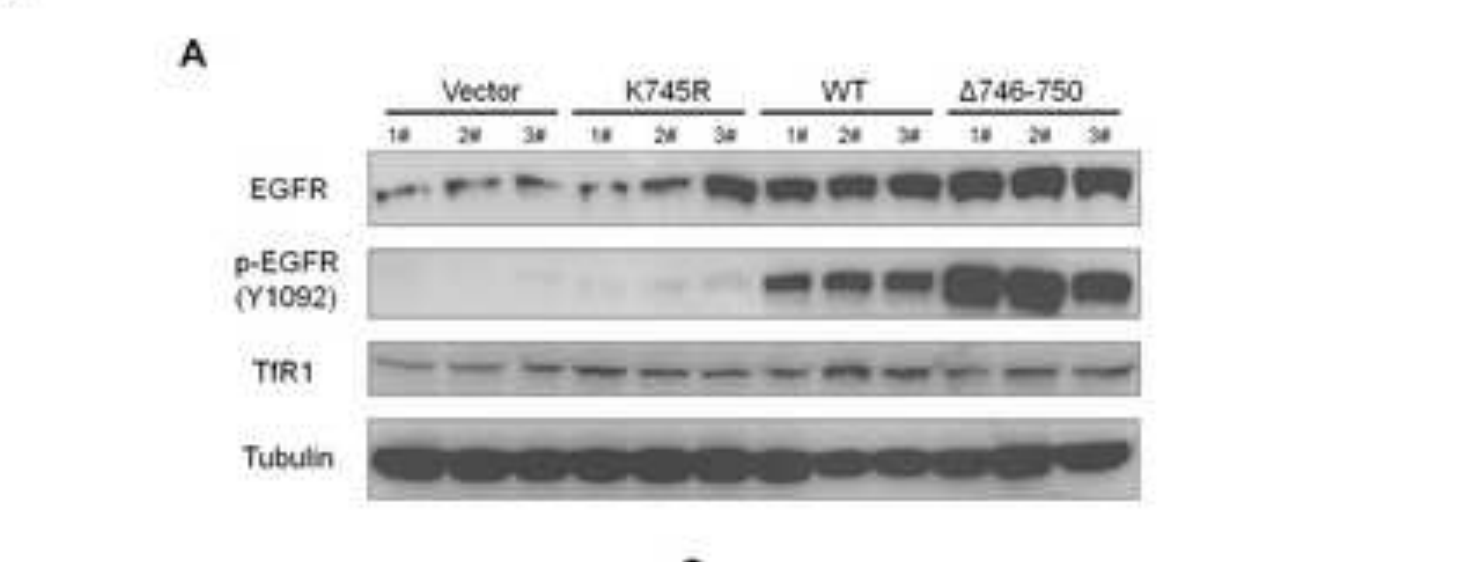

E

\begin{tabular}{|c|c|c|c|c|c|}
\hline & & \multicolumn{3}{|c|}{ Explession of p-EGFR (Y1092) } & \multirow[b]{2}{*}{ p value } \\
\hline & & Low & High & Total & \\
\hline \multirow{3}{*}{ Membeane TRR1 } & Low & $35(38.9 \%)$ & $13(14.4 \%)$ & $48(53.3 \%)$ & \\
\hline & High & $16(17.8 \%)$ & $26(28.996)$ & $42(46,7 \%)$ & \\
\hline & Total & $51(56.7 \%)$ & $39(43.3 \%)$ & $90(100 \%)$ & pe0.01 \\
\hline \multirow{3}{*}{ fron } & Low & $40(44,4 \%)$ & $13(14.49)$ & 53(5a.9s) & \\
\hline & High & $11(12.2 \%)$ & $26(28.996)$ & $37(41 . \%)$ & \\
\hline & Total & $51(56.7 \%)$ & $39(43.3 \%)$ & $90(100 \%)$ & peo.01 \\
\hline
\end{tabular}

B

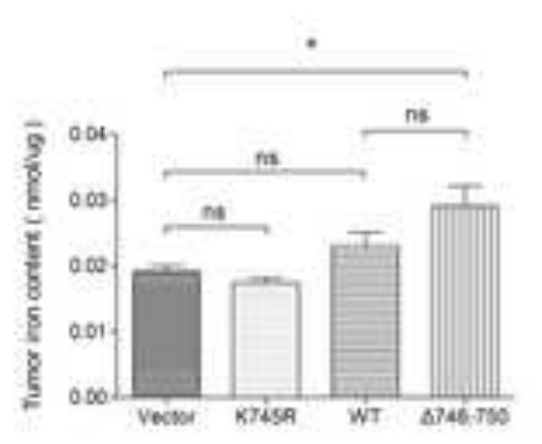

D

Case 1

D-EGFR C Y 1002

Case 2

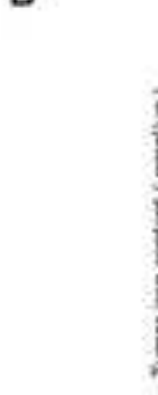

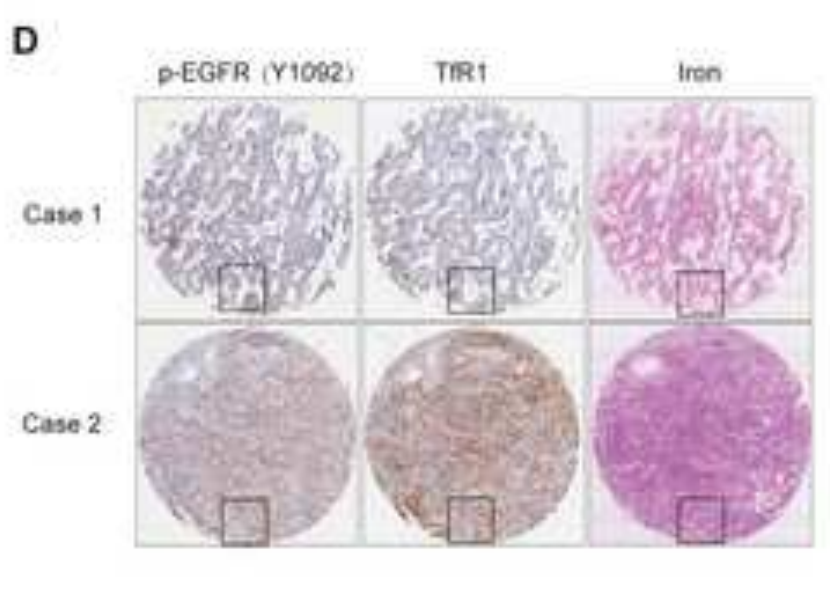

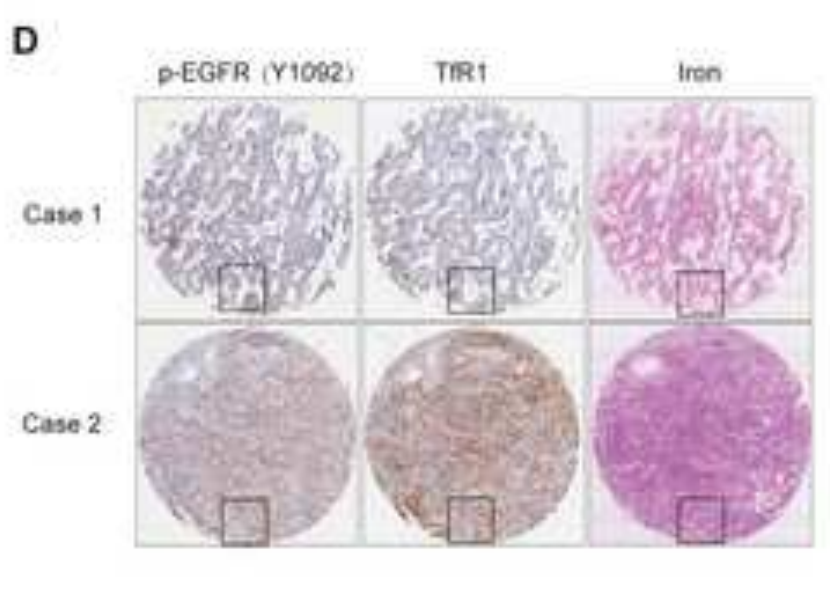

C

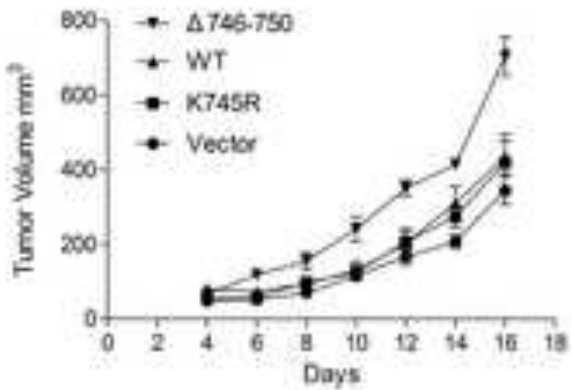

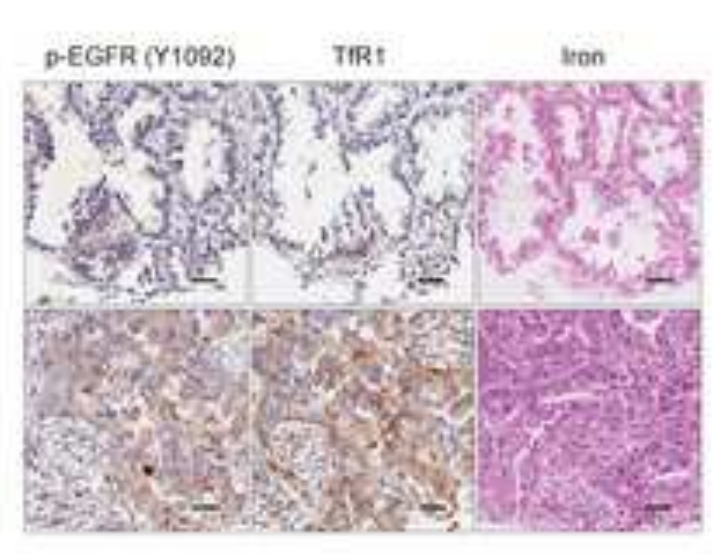

\begin{tabular}{l} 
B \\
Case \\
Case \\
\hline
\end{tabular}

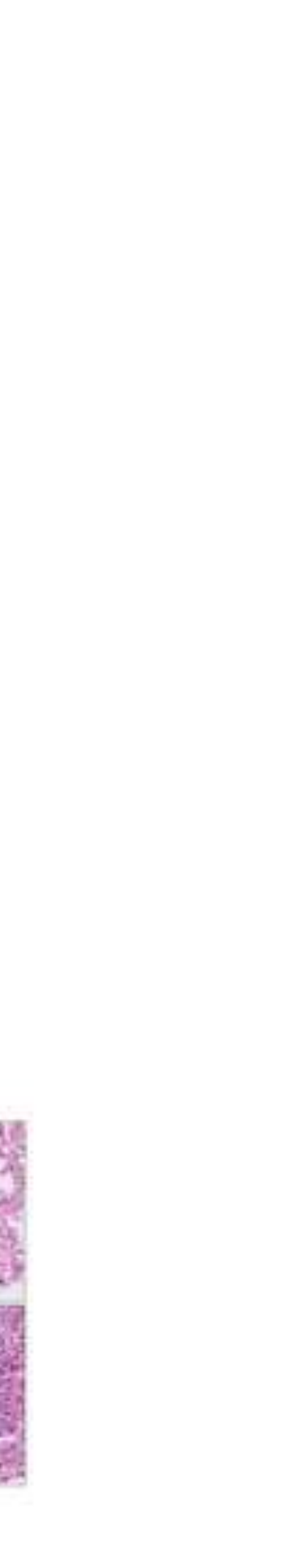

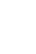

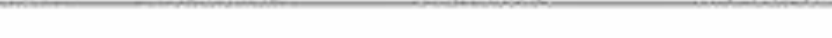

(1)

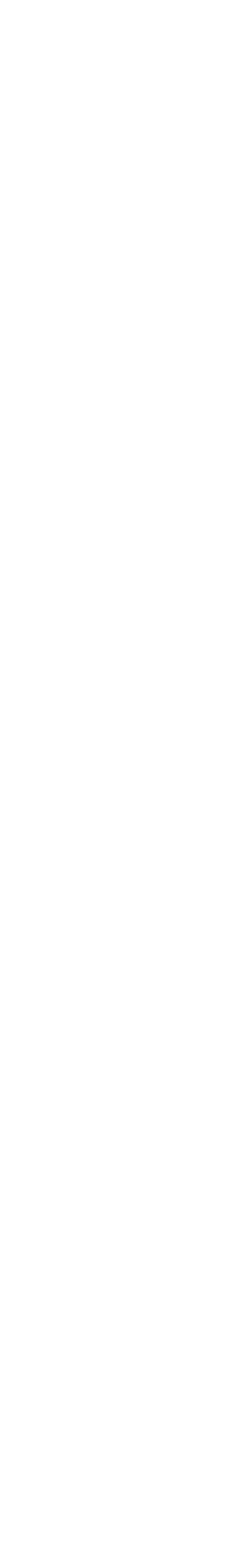

